\title{
Electra en Piñera
}

\author{
ELINA MIRANDA \\ Departamento de Lingüística y Letras Clásicas \\ Universidad de La Habana
}

\begin{abstract}
RESUMO: Este artigo é uma análise da Electra Garrigó de Virgilio Piñera, teatrólogo cubano, e das suas vinculações com o teatro trágico grego, sobretudo com a Electra de Sófocles, acrescida ainda de aproximações com autores modernos que trataram do mesmo tema. Apesar da inspiração grega, Piñera permanece um típico teatrólogo nacional, marcado pelos momentos de grande tensão social da sua época (a tragédia em apreço data de 1941). O conflito produzido pela excessiva autoridade dos pais sobre os filhos, latente neste mito, interessa-o por seu significado dentro da familia cubana.
\end{abstract}

PALAVRAS-CHAVE: Virgilio Piñera, Electra Garrigó, teatro cubano, teatro grego, literatura comparada.

A cuarenta años del acontecimiento teatral que Rine Leal calificara como "nuestra modesta batalla del Hernani"1 — la primera puesta en escena de Electra Garrigó (23 de octubre de 1948) - la obra causante de tal revuelo en el limitado ámbito intelectual de aquel entonces, es un hito bien establecido - polémica aparte - de nuestra dramaturgia. Con ella, como señalara el crítico mencionado, Virgilio Piñera "coloca de un golpe, de un salto admirable, el teatro cubano a la altura de su tiempo, de la poesía y la pintura cubanas del momento". esta búsqueda de contemporaneidad y cubanía que marca el quehacer teatral de los mejores representantes del teatro cubano de la etapa inaugurada, por así decir, con la Electra de Piñera, ${ }^{3}$ y un asunto tomado del viejo mito griego, no ha dejado de provocar extrañeza a la vez que ha sido punto de partida a veces, de posiciones críticas asumidas. No olvidemos que, según se cuenta, para algunos de los presentes en el estreno del teatro "Valdés Rodríguez", bajo los auspicios de la agrupación Prometeo, Electra Garrigó no era más que un escupitajo al Olimpo; mientras que términos como evasión, intelectualismo, influencia francesa, mimetismo, no han faltado a la hora de valorar el hecho en cuestión.

Mas, si tenemos en cuenta que en un reciente estudio doctoral sobre los personajes femeninos, únicamente, de la tragedia griega en la producción teatral española comprendida entre 1901 y 1984, la autora, María José Ragué-Arias, tuvo que consultar no menos de noventa y dos títulos, ${ }^{4}$ o el bien documentado libro del profesor Volker Rie- 
del sobre la presencia clásica en la literatura de la República Democrática Alemana a manera sólo de ilustración y sin pretender entrar en agotadoras enumeraciones, el horizonte se amplía.

Al paso de los siglos y de los años la literatura de los antiguos griegos - clásica por antonomasia - ha sido gustada en silencio, defendida a ultranza y atacada con igual beligerancia, echada al olvido por quienes no han sabido percibir más que el polvo acumulado en los volúmenes y evocada, una y otra vez, en las páginas de los más disímiles escritores, así como en la obra de músicos, pintores, coreógrafos, cineastas. En nuestro siglo $\mathrm{XX}$, a veces tan iconoclasta, al parecer, y circunscribiéndonos al teatro de su primera mitad, basta mencionar dos nombres de André Gide, Miguel de Unamuno, Eugene O'Neill, Jean Giraudoux, Jean Paul Sartre, entre otros, para formarnos una rápida idea de la persistente atracción y de la variada proyección con que las obras, los personajes, los mitos de los antiguos griegos se han mantenido vivos dentro del quehacer creador de nuestro tiempo.

Aunque abundan las teorías que en esta centuria han intentado explicar los mitos, resulta curioso constatar, junto con Gilbert Highet, que los autores modernos optan, en su mayoria, por el empleo de ellos a la manera en que lo hicieran los propios poetas antiguos, como "vehículo de significados morales y políticos para un público contemporáneo"6.

Si nos atenemos a Electra, la hija de Agamenón -ni siquiera mencionada con este nombre por Homero - , debe su verdadera trascendencia a los trágicos griegos. Tanto Esquilo como Sófocles y Eurípides presentaron esta figura del ciclo mítico referido a Troya en obras, por suerte, conservadas. Mas si para Esquilo es un personaje no protagónico, aunque en verdad significativo, en Coéforos, la segunda tragedia de la trilogía dedicada a exponer, como apuntara George Thomson, ${ }^{7}$ su teoría del origen del estado en relación - podriamos agregar - con la evolución del concepto de justicia, el cual para el trágico supone la consecución del equilibrio o armonización de las fuerzas en pugna, Electra es el centro de la tragedia de Sófocles, interesado fundamentalmente por el individuo; mientras que para Eurípides la venganza de los hijos de Agamenón es un buen pretexto para adentrar-se crudamente en los abismos de la naturaleza humana, una vez que los acontecimientos de Atenas, en medio de las guerras del Peloponeso, lo llenan de amargura y desconfianza frente a los ideales que enarbolara en sus primeras obras.

Un personaje, un mismo asunto, pero tres obras diferentes, puesto que los trágicos griegos no vacilan en alterar los elementos brindados por el mito en función de la expresión de sus ideas. Esquilo, sin reparo alguno, introduce en el conflicto de la casa de Atreo la fundación del Areópago y con ello, desde la escena, apoya la medida política que por entonces agitaba a Atenas, al recortar Efialtes el poder de este tribunal, bastión aristocrático, mientras proclamaba que lo restituía a su verdadera misión, dirimir únicamente pleitos en torno a derramamientos de sangre. De esta manera los demócratas le arrebataban a los nobles la última arma institucional de que disponían para hacerse sentir oficialmente en la vida de la polis.

Por otra parte, si en Coéforos la anagnórisis de los hermanos antecede a la venganza de modo que Orestes mata a su madre y a Egisto no solo para obedecer el 
mandato de Apolo, sino por propia decisión al hacer suyos, a través del diálogo con su hermana, los males de su casa, Sófocles retarda el encuentro de los hermanos, para que Electra, uma vez perdida toda su esperanza ante la noticia de la muerte de Orestes, cobre su verdadera dimensión como protagonista trágica.

En lo que respecta a Eurípides, este nos oferece una visión totalmente novedosa del mito. Electra ha sido alejada del palacio mediante su matrimonio con un hombre pobre y, para atraer a su madre Clitemnestra, decepcionada por la vida, a la celada preparada, le hace llegar el falso anuncio de que ha tenido un hijo. Sin embargo, aunque el autor de tragedias se mueve con relativa libertad dentro del mito - y lo modifica en tanto le sea necesario, al tiempo que lo enriquece con su nueva interpretación -, no pierde de vista sino, por el contrario, procura conscientemente el recuerdo de la obra de sus antecesores. Cuando se inicia Coéforos, Electra se nos presenta como una joven doncella que no sabe cómo actuar ante el pedido de su madre, quien, asustada por un sueño, la ha enviado a aplacar los manes del padre asesinado y el coro tiene que aconsejarla. Pero después del encuentro con su hermano, cuando ambos, a través de un largo kommós, ${ }^{8}$ comparten sus mutuos dolores y se reconocen como víctimas del crimen de la madre, Electra emerge como fiera vengadora. Esta será la heroína de Sófocles, quien seguro de su arte y poseedor de su propia interpretación del mundo, no rehúye la confrontación con su gran predecesor y se aprovecha de la evocación voluntariamente suscitada para constatar, subrayar y aun para economizar un efecto. Como señalara Headlam, hace ya muchos años, "en la Electra de Sófocles no hay apenas algún toque que en una forma u otra no se encuentra ya en Esquilo". 9

Erigida en recordatorio viviente, la Electra sofoclea desafia el orden estabelecido en espera del momento de la venganza. Vejada y obligada a una existencia servil, su espiritu se mantiene libre a diferencia de su hermana Crisótemis, aparentemente libre, pero en verdad sometida a Clitemnestra y Egisto. Sin embargo, Electra sabe que ella hubiera podido ser de otra manera - la inocente joven del primer episodio de Coéforos - si otra hubiera sido la situación. Al tiempo que el contrapunteo entre Electra y su madre nos permite vislumbrar lo que de Clitemnestra hay en ella en anticipo a su grito terrible. "Dale, si puedes, doble herida!" "10 mientras que cierta angustia momentánea, experimentada por Clitemnestra ante la noticia de la muerte de su hijo, nos enseña que también ella un día fue como pudo haber sido Electra.

La valoración del obrar humano acerca a Sófocles, a medida que desarrolla su quehacer como trágico, cada vez más a la indagación psicológica de los móviles de la actuación y le hace descubrir una rica gama de matices, como cuando Electra pasa del dolor más profundo al júbilo más estremecedor en rápida transición dentro de la obra.

Las tensiones extremas que pesan sobre la protagonista, quien, cogida entre apariencia y realidad, pasa en breve tránsito de la esperanza a la desolación, de ésta a la decisión de consumar la venganza, para desembocar en la alegría del reencuentro con Orestes y el fin de sus dolores con la muerte de los asesinos de Agamenón, tienen necesariamente que conturbar su espíritu. Y esto, unido a la analogía ya señalada con Clitemnestra y la continua evocación de la tragedia esquilea, son elementos chave para 
estimar, junto con Thomson, que, a diferencia de lo dicho en ocasiones, esta tragedia no culmina con la liberación y el triunfo, sino que el silencio final de Electra pone de manifiesto la desolación y el vacío en que cae una vez que su objetivo, su razón de ser, se ha cumplido. Como comenta el autor citado "no hay salida, y aquí es donde yace lo trágico: la tragedia de una naturaleza apasionada que en la realización de su vitalidad es cogida como en un vicio y aplastada. ${ }^{11}$

$\mathrm{Y}$ es precisamente este ambiente sugerido por Sófocles al final de su obra, el que impregna la tragedia de Eurípides en torno a Electra. Alejada de la corte, casada con un noble arruinado que vive de su trabajo y respeta la doncellez de la hija de Agamenón, Electra espera la venganza en una choza en los confines de Micenas, sin ejercer ningún peso en la vida de Egisto y Clitemnestra. Esta, con los años y la cotidianidad, vive decepcionada; ha salvado a su hija de la muerte, es capaz de ser indulgente $y$, fatigada, confiesa que sus acciones no le han traído alegría. De esta manera Eurípides subraya la sordidez del crimen, de modo que, en este clima espiritual, la pasión que bullía en Electra deviene horror de lo cometido, una vez que la venganza se ha realizado en medio de engaños. Al igual que en Esquilo, el matricidio centra la preocupación del trágico, pero para su censura. También en detalles, como en la escena del reconocimiento, o en el hecho de que Egisto enfrenta la muerte primero que Clitemnestra, Eurípides tiene presente a Esquilo, si bien en cuanto a la repercusión en el ser humano aventura pasos que lo adentran en la desolación que intuímos en la Electra sofoclea.

Así pues, son los propios autores antiguos quienes pusieron de manifiesto las posibilidades polisémicas del mito y sus ventajas, como asunto conocido, de permitir que toda la atención del receptor se concentre en el desarrollo del tema y en la interpretación que de él hace el autor, al tiempo que dieron ejemplo de cómo debe entenderse creadoramente la tradición, al hacer de esta no una rémora sino un acicate a su propio quehacer. Sirva esta lección de los antiguos de buen antídoto para aquellos que se escandalizan con el empleo que del mito hacen los autores modernos o que, por el contrario, consideran la vielta al mito solo como una muestra de dilectantismo. Siempre que un nuevo autor retoma un viejo motivo de la tradición clásica, ha de contar con las evocaciones que su sola mención provoca en el público y, a su vez, al replantearlo según su óptica peculiar y la de su época, lo enriquece. Por ello, el uso de las figuras míticas se presenta como un reto para cualquier escritor contemporáneo, pero también le proporciona un expediente adecuado para, como señala Highet, presentar "temas que puedan tratarse con vigorosa sencillez, temas que tengan la bastante autoridad para sostenerse por sí mismos, sin necesidad de masas de detalles realistas o 'impresionistas' que los hagan convincentes", 12 sin olvidar que los mitos son también fuente de poesía.

La firme resistencia de Electra, en contraste con su delicadeza de joven doncella, su fuerte vínculo con el padre y su oposición a la madre, su influencia sobre su hermano, su voluntad de justicia, son, entre otros, rasgos que han atraído la atención de los autores contemporáneos sobre esta figura de la tragedia griega, particularmente en el teatro. Ya em 1901 Benito Pérez Galdós estrena su Electra en un intento de renovación de la temática teatral española, mientras que de 1903 data la obra de Hugo von Hof- 
mannsthal que se regodea en la venganza. En 1931 Eugene O'Neill presenta su trilogía A Electra le sienta el luto, mientras que Jean Giraudoux escribe su Electra en 1937 y Jean-Paul Sartre hace representar Las moscas en 1943, dos años después de que Virgilio Piñera, como bien este hiciera notar, había escrito su Electra Garrigó. En este renascer de los viejos mitos que torna de nuevo familiares los nombres de Prometeo, Sísifo, Electra, para cualquier hombre de mediana cultura en esas décadas de nuestra agitada centuria, no es nada raro un joven cubano de veintinueve años, $c$. solo tres de ensayo como dramaturgo, se sintiera atacado por el "bacilo griego", como el propio Piñera lo calificara. ${ }^{13}$

En el año 41 en Cuba la revolución del treinta se había ido a bolina, en el gráfico decir de Raúl Roa, Batista era dueño del poder, la corrupción era moneda corriente y la frustación impregnaba su marca en el sentir de muchos. En el terreno de la cultura la década del cuarenta conoció serios aunque aislados esfuerzos de resistencia frente al desinterés oficial y la mediocridad conformista y aplastante que se generalizaba. En este ambiente se funda, también en el 41, Teatro Universitario, el cual ese mismo año estrena Antígona, de Sófocles, Coéforas, de Esquilo e Ifigenia en Taúride, de Goethe. En 1943 surge Teatro Popular, dirigido por Paco Alfonso, que durante dos años trabajó con ahínco por vincular la escena a los trabajadores. En el 44, antiguos alumnos de la Academia de Artes Dramáticas fundan $\mathrm{ADAD}$ y en el 47 aparece el primer número de la revista teatral Prometeo, para poco después constituirse como grupo.

Las largas jornadas de ensayo a las que se sacrificaba las horas de descanso para uma representación única, era lo usual por entonces para todos aquellos que se esforzaban por hacer teatro y, sin embargo, un recorrido por las carteleras de la época muestran un amplio repertorio donde clásicos y contemporáneos se daban la mano. En el año 48, cuando al fin sube a escena Electra Garrigó, Teatro ADAD ofrecía funciones de $E l$ avaro, de Molière, Ligados, de Eugene O’Neill, La más fuerte, de Sirindberg; mientras que el Patronato del Teatro representó Un tranvía llamado deseo, de Tennessee Williams, Penélope, de Somerset Maugham y Teatro Universitario brindaba una memorable representación de Medea, entre otros títulos.

Aunque funciones únicas ante un escaso número de espectadores, estos intentos teatrales de la década del cuarenta posibilitan la formación de teatristas, un cierto ambiente - si bien restringido - con aires renovadores, y contribuye al replanteo de la escena cubana: hacer un teatro que sea una auténtica expresión de nuestros problemas y modo de ser a la por que contemporáneo y arte verdadero es, indudablemente, un presupuesto latente para los dramaturgos que surgem o se forman en esta época: el propio Piñera, Carlos Felipe, cuya obra El chino se estrenó en el 47, y Rolando Ferrer, un poco más joven, quien hará representar sus primeras obras en los años cincuenta.

Si en el 41 Piñera, estudiante de Filosofia y Letras de la Universidad de La Habana, no puede sustraese al "bacilo griego", en un contexto cultural, aunque limitado, no quiere ello decir que lo enfrente al margen de su condición de cubano. El mito de Electra le toca muy de cerca en cuanto a las relaciones familiares se refiere y le brinda 
el distanciamiento necessario para un primer acercamiento. Años más tarde, ya en plena madurez y luego de un viaje a Buenos Aires, volverá al tema de su realidad familiar para abordarlo entonces de forma directa y descarnada en Aire frío. Mas, independientemente de las connotaciones autobiográficas, el tópico de la familia, específicamente - como aclara en las notas al programa de la primera puesta en escena - "el conflicto producido por la dictadura sentimental de los padres sobre los hijos" latente en el mito, le interesa por su significación dentro de la familia cubana.

Por ello, consciente de las diversas vias para plantearse el mito, rechaza explícita. mente tanto el "poner en época actual los conflictos de uma familia griega del siglo $\mathrm{V}$ "14 como el brindar una versión moderna al estilo de O'Ncill. Elige su propio camino y ello se patentiza en el mismo título seleccionado: no se trata de una Electra más para agregar a la relación de piezas con este nombre, sino ia dota con un - apellido que la ubica en un ámbito determinado: Electra Garrigó.

Aunque encabeza las notas al programa con la afirmación expresa de su filiación sofoclea, se mueve dentro del mito con una libertad digna de Eurípides. Cuando la obra comienza Agamenón aún no ha muerto, Clitemnestra Pla y su amante nì siquiera han tomado la decisión de asesinarlo, Orestes no ha salido nunca del hogar y solo Electra, al igual que en la tragedia, es una joven en edad casadera, pero atormentada por los conflictos de su casa. Ya O'Neill había retrasado el momento de la muerte de Agamenón, pero solo en Piñera Electra, Orestes, Agamenón, Clitemnestra y Egisto conviven familiarmente. Los clásicos antiguos no son para Virgilio Piñera reverenciados objetos museables, sino lección viva y como ellos no vacila en reformular el mito en función del tema que se propone llevar al ánimo de los espectadores.

Sin embargo, se identifica con Sófocles en tanto Piñera no se interesa por las implicaciones políticas de la muerte de Agamenón o por la consideración ética del matricidio, sino que la figura de Electra en busca de su realización como personalidad centra toda su atención. Por ello, no obstante las diferencias argumentales y de tratamiento dramatúrgico, no cabe dudas cuando el teatrista cubano asiente que "Electra Garrigó, sale, claro está, del drama de Sófocles", al tiempo que nos pone en guardia para no aceptar superficialmente su propia declaración cuando limita los puntos de contacto a los personajes, atmósfera y elocución en su afán de subrayar la raigambre del tema elegido.

La Electra de Piñera, como su ilustre antecesora sofoclea, es la única conturbada y consciente de la necesidad de resistencia frente al ambiente familiar que coacta su desarrollo pleno como individuo y amenaza con ahogar su personalidad. Pero, en la tragedia griega, la heroína cifra sus esperanzas en el retorno de su hermano y solo la noticia de la muerte de este la determina a actuar por sí sola de modo que se revela en su verdadera dimensión como carácter singular, mas su acción no está condicionada por la necesidad intima de su afirmación personal, como si ocurre con Electra Garrigó, quien además, sabe desde el principio que solo puede contar consigo misma, como bien se encarga el autor de mostrar tanto en la invocación a los no-dioses como en detalles del tipo de la noticia de la muerte del pretendiente, que suple la relativa a Orestes en 
Sófocles. Esto ya no tiene una función de detonante, sino que afirma la determinación de Electra, que a la pregunta de Egisto Don: "Y ahora ¿qué vas a hacer, pobre Electra? ¿No era el pretendiente tu suprema esperanza?", 15 contesta segura: "Nunca hay una suprema esperanza. En cambio me quedaré en esta casa por el resto de mis dias". 16 Nacida de la heroína de Sófocles, Electra Garrigó se perfila entonces como personaje autónomo, creación y portavoz de Piñera, puesto que está marcada por las inquietudes y cuestionamientos que la época promovía en el autor, como este confesara años después, en 1960, en el prólogo a la edición de su teatro: "en la época en que escribí Electra, meditaba a diario en esto: en medio de tanta confusión, ¿con quién contar? Y la respuesta era la reducción al absurdo: conmigo mismo, y digo reducción al absurdo pues el ser humano que sólo cuenta consigo, está atado de pies y manos", 17

Consecuente con esta concepción, Electra Garrigó, una vez conseguido su propósito, se queda sola - como el personaje de Sófocles o la Lavinia de O'Neill — en una casa donde no hay erinias ni remordimientos, ni espectros, sino que todo deviene Electra: la puerta Electra, el rumor Electra, el ruido Electra, el trueno Electra. El mito no es ajeno ni simple pose teatral, sino que una vez más ha sido recreado, ahora a lo Piñera.

Este rejuego del autor con los elementos del mito y en general de la tradición literaria en torno a él generada, con los aportes de escritores contemporáneos incluidos, y su puesto en función de su propia óptica en relación con sus circunstancias, sin olvidar los reclamos de su posible público, se hace patente en toda la obra. Al igual que en las antiguas tragedias, la acción se desarrolla en un mismo lugar con una escenografia muy sencilla: un portal con columnas que recuerda nuestras casas coloniales, pero que también conlleva una reminiscencia de los antiguos griegos, con un manejo de la luz indudablemente contemporáneo. Como la mayoría de las piezas teatrales modernas consta de tres actos, mas con la presencia de un coro que entona décimas, a la manera que se hacia por entonces con la guatanamera en un conocido programa radial para emmarcar dramatizaciones de crímenes pasionales.

Una vez que el coro, siguiendo la tónica de sus antecesores griegos, nos ha ubicado, caracterizado al personaje principal a grandes rasgos, presentado la situación e introducido a Electra, la confrontación con la tragedia sofoclea se explicita con la invocación a la luz, solo que ya no se trata del simple saludo a la luz del día, del día de la llegada de Orestes, de la heroína griega sino que esta luz está cargada con el peso simbólico que le diera Giraudoux en su propria Electra, aunque ahora pasa de referencia a presencia viva. Mas la solemnidad del discurso, la evocación de la tragedia, es rota por la entrada del pedagogo centauro y su llamado al orden. ${ }^{18}$

A partir de aquí este recurso - usado también por los antiguos cómicos griegos en sus parodias mitológicas del llamado período medio - se convierte en rasgo definidor de la obra. Los personajes, la situación, el tema son propios de tragedia, pero Virgilio Piñera, como él mismo ha dejado constancia, no tenía interés alguno em "repetir de cabo a rabo a Sófocles o a Eurípedes"19, y sí procurar una obra que llegara a su público, que "sacara al espectador de su luneta" flicto a pesar de su viejo atuendo: apela, entonces, a una "sistemática ruptura de la 
seriedad entre comillas" ${ }^{\text {21 }}$ como rasgo peculiar de la idiosincrasia del cubano, conformada a modo de vital respuesta ante los frusteantes avatares históricos vividos por el pueblo en su formación y consolidación como nacionalidad.

$\mathrm{Y}$ en efecto, más que el patio colonial, la guantanamera, el uso de nombre y apellido, los actores negros, el traje de Egisto o la alusiva fruta bomba, el sabio empleo de esta ruptura de ambiente por un giro inesperado, este oportuno contrapunteo entre tragedia y comedia, este fino sentido del ridículo que recorre toda la obra, es el instrumento clave mediante el cual Virgilio Piñera hace suya y de su público la vieja tradición, la pone a su servicio y demuestra su estatura de dramaturgo: el mito adquiere carta de ciudadanía al tiempo que proyecta a un ámbito mucho más amplio elementos hasta entonces casi siempre confinados a escenas de costumbrismo local.

Acto lleno de dinamismo por el continuo movimiento de los personajes, de los cuales solo Electra se mantiene prácticamente todo el tiempo en escena, y por el sentido de efecto teatral, que incluye la representación dentro de la representación, sirve para que Electra ponga en evidencia la verdadera faz de la relación padre-hijo: no es el cariño, sino el egoísta deseo de prolongarse el verdadero móvil. "Llamas familia a tu propia persona multiplicada",22, le espeta Electra a Agamenón.

La rivalidad madre-hija en torno a Orestes, más que la confrontación Electra-Clitemnestra de Sófocles, recuerda a Giraudoux, mientras que la relación de Clitemnestra $\mathrm{Pla}$ con su hijo tendría acentos de O'Neill, al tiempo que versión con rasgos caricaturescos de la tradicional madre criolla, tan bien representada por la Doña Rosa, de Cirilo Villaverde $y$, en general, en la literatura cubana. A su vez, las verdades dichas en contextos en que no lo parecen, remiten de nuevo a la visión sofoclea; pero estos pequeños homenajes y algún que otro más, muestran, por contraste, que Piñera maneja los hilos con soltura, sin perder las riendas al poner los más disímiles elementos en función de su propria expresión.

Después del enfrentamiento entre Electra y Agamenón, en un típico agón de tragedia griega, en que la hija deja al descubierto la verdad de las relaciones familiares, en el segundo acto se pasa a los hechos. Convencida de que no habrá marido para ella ni viaje para su hermano, que no habrá Electra ni Orestes mientras Agamenún y Clitemnestra impongan su ley, Electra inicia la lucha a la que arrastrará a su débil e indeciso hermano. Aprovecha la oposición mutua de sus padres para decidir ella y no Clitemnestra la suerte de Agamenón.

Según la Odisea, Egisto había sido el artífice y ejecutor de la muerte de Agamenón, pero Esquilo había dado en su trilogía este papel a Clitemnestra, mientras que Egisto, cobarde y tiránico, protegido por sus faldas, solo servía para subrayar la sordidez del crimen. La impronta del personaje esquileo fue tal que no hay version posterior que niegue a la fuerte personalidad de Clitemnestra la autoría del hecho.

Sin embargo, para Piñera es Electra quien, decidida a su acción "sanitaria", pone en movimiento los resortes del odio y la voluptuosidad de la madre para que esta decrete la eliminación del "gallo viejo" y usa a Egisto como agente. Como resultado de tal exacerbación en forma de juego de gallinita ciega y pelea de gallos, la muerte se consu- 
ma. El coro, por primera vez usado dentro del acto y no para enmarcarlo, retoma una antigua función de cortina temporal que propicia el tránsito y la distensión ${ }^{24}$. Clitemnestra se preocupa entonces por los vivos. Quiere alejar a Electra, mas esta, que anteriormente ha definido el destino con necesidad, con frialdad concentrada pero con efecto análogo al grito apasionado de "Hiere dos veces", sopesa lo alcanzado y se prepara para el próximo paso: "Ya tengo a Agamenón. Ahora ¡Clitemnestra! Eso es: una cuestión sanitaria, una mera cuestión sanitaria". ${ }^{25}$

Quando concluye el Agamenón, no queda duda: Clitemnestra no ha puesto fin a la cadena de crímenes de la casa de Atreo, como ella pretendía, sino que se ha convertido en un eslabón más y como tal la retribución, encarnada en el vengador Orestes, no se hará esperar. Vínculo semejante al usado por Esquilo entre las tragedias de su trilogía, tiene Piñera entre su segundo y tercer actos, como bien se encarga de subrayar el coro. Agamenón ha muerto. Es el turno ahora de Clitemnestra Pla: pero Electra Garrigó no se apresura: para que la liberación buscada se produzca, Orestes ha de definirse.

Por ello, a diferencia de los dos actos anteriores, no es Electra, sino Orestes, quien lo inicia y tendrá a su cargo el monólogo, aunque antecedido en esta ocasión por un escena que, al retomar motivaciones dispersas en los actos anteriores, prepara la reflexión, el "conócete a tí mismo" - según la célebre sentencia griega - de Orestes, y, a su vez, esta desembocará en la anagnórisis de los hermanos.

Para Aristóteles - quien al teorizar sobre la tragedia, tenía muy en cuenta el modelo brindado por Sófocles -, peripecia y anagnórisis eran elementos consustanciales al género; mas sobre todo admiraba la forma en que el autor de Edipo Rey manejaba estos recursos, puesto que en Sófocles el cambio de fortuna, la peripecia, surgía del proprio desarrollo interno de la acción y la anagnórisis lograba su mayor efectividad dramática ên el autorreconocimiento de Edipo. E indudablemente, Virgilio Piñera tenía bien presente estas cualidades sofocleas, no solo cuando en el diálogo de los hermanos evoca el pasaje de Edipo y la Esfinge, sino porque en esta escena se devela la personalidad de Orestes, y Electra lo identifica como digno hermano suyo. No se trata, como en Esquilo, de que Orestes sienta suya la situación de su hermana y de su casa y de ahí su voluntad de acciór, sino de que al fin toma conciencia de sí y de la madeja de relaciones familiares que lo envuelve.

Una vez que la muerte de la madre se ha concertado por los hermanos, los sirvientes, Egisto, abandonan el barco que se hunde, la casa que, como advierte Clitmnestra Pla, ha empezado a convertirse en Electra. Y hasta Orestes siempre dependiente como lo prefiguraron los clásicos, pero lo perfiló O’Neill —, se vuelve a su hermana, ya cometido el crimen, y esta lo obliga a partir. Solo Electra queda con Electra, en "reducción al absurdo" de quien solo cuenta consigo, según hiciera explícito el autor años más tarde.

Buen conocedor del mito de Electra en sus distintas variantes literarias, clásicas y modernas, y del género trágico - del cual toma no solo aspectos externos sino también elementos estructurales específicos - la afinidad con Sófocles se hace patente desde el ampleo de detalles hasta coincidencias de intereses, enfoques interpretativos y aun de 
modos de asumir la realidad. Sin embargo su Electra Garrigó no es mero ensayo academicista para evadir la corrupción de un medio social que, no obstante, se hace presente en reiteradas referencias: son precisamente sus circunstancias, personales y sociales, las que inciden, ya no en la selección del mito, sino en su forma de apropiárselo.

Virgilio Piñera aceptó el reto de transitar por caminos ya recorridos tantas veces y por tantos y disímiles creadores y puso de manifiesto que el acercamiento a los clásicos supone un aprovechamiento de sus verdaderas lecciones y no copia extema o mero barniz. De acuerdo con sus palabras, "Electra, Agamenón, Clitemnestra tendrán que seguir siendo ellos mismos" ${ }^{25}$, pero si los trágicos conocían bien a su pueblo - ¿no es este el quid para quien desea disfrutar de las ventajas que el empleo de tales personajes supone al tiempo que procura una real comunicación con su público?. Esta fue la elección del joven teatrista cubano atacado por el "bacilo griego". Usa, pues, las viejas figuras trágicas con increíble libertad, con inventiva e ingenio porque está seguro de lo que quiere expresar y del modo en que ha de hacerlo para obtener el efecto deseado. Selecciona, combina, innova, al tiempo que hace gala, sin duda ostentosa, de la tradición literaria de la cual se apropia, de manera que no quede otro remedio que, como reclamara alguna vez, leerlo en Piñera.

\section{Notas}

1-Rine Leal, 1967, p. 203.

2-Ibid., p. 205.

3- Aunque estrenada en 1948, fue escrita en 1941.

4- María-José Ragué-Arias. Resumen de la tesis doctoral "Los personajes femeninos de la tragedia griega en el teatro español del siglo $X X^{\prime \prime}$, p. 6.

5- Volker Riedel, 1984.

6- Gilbert Highet, La tradición clásica, p. 347, t.2.

7- George Thomson, 1982, p. 412.

8- Diálogo contado.

9- Citado por Thomson, 1982, p. 476.

10-Sófocles, 1978, p. 261.

11- Thomson, 1982, p. 484.

12- Highet, op. cit., p. 348.

13- Virgilio Piñera, 1960, p. 9.

14- Ibid.

15- Ibid.

16- Piñem, 1960 , p. 55-6.

17- Ibid., p. 13.

18- Según Piñera: "Electra declama al modo de nuestros políticos que se pasaban la vida diciendo discursos de vacía retórica, método infalible para adormecer al pueblo" (op. cit., p. 14). De ahí que la intervención del pedagogo sirva para poner de manifiesto el carácter no derrotista de Electra (declamar/clamar). También en el segundo acto el monólogo de Electra es interrumpido por Egisto y Clitemnestra, quienes creen que está representado, y marca el contraste entre ambos tal 
como lo entiende la madre (Electra declara; ella vive).

Por otra parte la figura del pedagogo-centauro hace preguntarse si Piñera no tuvo en cuenta el símil que Sófocles pone en boca de Orestes, quien compara a su pedagogo con un noble caballo, sin olvidar que dentro del mito griego a partir de Quirón como educador de Aquiles, la relación pedagogo-centauro estaba fijada.

20- Piñera, 1960, p. 9.

21-Ibid., p. 10.

22-Ibid.

23-Ibid., p. 39.

24- También será usado de este modo en el tercer acto, al cual, por otra parte, no cerrará pues las palabras finales quedan en boca de Electra.

25-Op. cit. supra, p. 9.

26-Ibid., p. 1.

\section{Referências Bibliográficas}

LEAL, R. VP o del teatro como ejercicio mental. In: En primera persona. La Habana: 1967.

PIÑERA, V. Electra Garrigó. In: Teatro completo. La Habana: 1960.

PIÑERA, V. Piñera Teatral. In: Teatro completo. La Habana: 1960.

RAGUÉ-ARIAS, M.-J. Resumen de la tesis doctoral "Los personajes femeninos de la tragedia griega en el teatro español del siglo XX". Universidad de La Habana.

RIEDEL, V. Antikerezeption en der Literatur der Deutschen Demokratische Republike. Berlin: 1984.

SÓFOCLES. Electra. In: Tragedias. La Habana: 1978.

THOMSON, G. Esquilo y Atenas. La Habana: 1982.

MIRANDA, E. Electra dans Piñera. Clássica, São Paulo, 4: 203-213, 1991.

RÉSUMÉ: Cet article est une analyse de l'Electra Garrigó de Virgilio Piñera, dramaturge cubain, et de ses rapports avec le théatre tragique grec, surtout avec l'Electre de Sophocle, ajoutée aussi d'approximations avec les auteurs modernes qui ont traité du même sujet. Malgré l'inspiration grecque. Piñera demeure un dramaturge national typique, marqué par les moments de grande tension sociale de son époque (la tragédie en question date de 1941). Le conflit produit par l'excessive autorité des parents envers leurs enfants, sous-jacent dans ce mythe, l'intéresse par sa signification à l'intérieur de la famille cubaine.

MOTS CLÉs: Virgilio Piñera, Electra Garrigó, théâtre cubain, théâtre grec, littérature comparée. 